\title{
DESENVOLVIMENTO DO SISTEMA FINANCEIRO E EXPORTAÇÕES BRASILEIRAS: UMA ANÁLISE PARA O PERÍODO DE 1995 A 2014
}

\author{
Fernanda Aparecida Silva * \\ Leonardo Bornacki de Mattos ${ }^{\dagger}$
}

\begin{abstract}
Resumo
Este trabalho buscou mensurar como o grau de desenvolvimento financeiro do Brasil e dos principais parceiros comerciais afetou o valor exportado pelo país; quantificar a relação entre dependência financeira de setores selecionados, grau de desenvolvimento financeiro e o valor exportado pelo Brasil em cada setor. A análise é operacionalizada por meio da estimação do modelo gravitacional utilizando o método de regressão quantílica com correção para a seletividade amostral. De maneira geral, os coeficientes estimados indicaram que o desenvolvimento financeiro brasileiro não é importante estatisticamente para determinar as suas exportações. Todavia, quando se analisou o grau de dependência financeira dos setores, encontrou-se relação positiva e significativa entre o desenvolvimento financeiro nacional e o valor exportado.
\end{abstract}

Palavras-chave: desenvolvimento financeiro, exportações, modelo gravitacional.

\begin{abstract}
This paper aimed to measure how the degree of Brazilian financial development and of its main trade partners affected the value exported by the country; quantify the relationship between financial dependence of selected sectors, degree of financial development and the value of Brazilian exports in each sector.The analysis was operationalized through the estimation of the gravity model using quantile regression with correction for the sample selection. Generally, the coefficients were estimations pointed out that financial development of Brazil was not important to determining its exports. Nevertheless, when the degree of financial dependence of the sectors was analysed, we found a positive and significant relationship between national financial development and value exported.
\end{abstract}

Keywords: financial development, exports, gravity model.

JEL classification: JEL: F10, F14, F36, G20.

DOI: http : / /dx.doi .org/10.11606/1980-5330/ea142487

\footnotetext{
* Universidade Federal de Viçosa. E-mail: fernandasilvaufv@gmail.com

${ }^{\dagger}$ Universidade Federal de Viçosa. Bolsista de produtividade em pesquisa do CNPq. E-mail: lbmattos@ufv.br
} 


\section{Introdução}

O sistema financeiro brasileiro, segundo o Banco Central - BACEN (2015), foi marcado por reformas na década de 1960 que segmentaram o mercado. Em 1988 , foram criados os bancos múltiplos, os quais poderiam, por meio de carteiras, operar nas diversas áreas nas quais atuam as instituições singulares. Após a implantação do Plano Real, houve redução dos níveis inflacionários e expansão da abertura comercial, que, além de exigir maior competitividade dos produtos domésticos, revelou o grau de ineficiência de alguns setores, que passou a refletir-se na incapacidade de honrar os empréstimos concedidos pelos bancos. Ademais, a política monetária restritiva contribuiu para aumentar o grau de inadimplência para com o sistema bancário, o que evidenciou a fragilidade de algumas instituições financeiras diante do novo ambiente econômico. Nesse contexto, foi necessário o estabelecimento de medidas no âmbito do Conselho Monetário Nacional e do Banco Central de forma a reestruturar e fortalecer o sistema financeiro ${ }^{1}$. De acordo com o BACEN (2017), em 1998 o Brasil possuía um sofisticado sistema financeiro, no qual os bancos, modificando tecnologias e processos de produção de serviços, demonstraram maior flexibilidade para se adaptarem às condições de economia estável.

Ao analisar os dados do Sistema Financeiro Nacional nos últimos 20 anos, de acordo com o Banco Central (BACEN 2017), em dezembro de 1994, o número de agências bancárias no Brasil era de 17.400, sendo que esse valor chegou a 23.126 em dezembro de 2014. Quanto ao número de instituições, incluindo bancos comerciais, múltiplos e caixa econômica, em 2014, havia 154 em funcionamento no país. Já no ano de 1994, esse número chegou a 246 instituições financeiras. Em se tratando dos dados do Global Competitiveness Report (2015), o índice de solidez dos bancos brasileiros foi, em 2015, 6,09, em uma escala de 1 a 7 , sendo 7 o melhor valor. Todavia, ao analisar o índice de facilidade de acesso ao crédito, o valor foi de apenas 2,66, e o Brasil ocupou a $85^{\text {a }}$ posição no ranking mundial, em um total de 153 países.

Existem na literatura diversos estudos que consideram o desenvolvimento do sistema financeiro um instrumento relevante para o bom funcionamento de diferentes áreas da economia. Nesse contexto, pode-se destacar Silva \& Porto Júnior (2006), que argumentaram que o bom funcionamento do sistema financeiro permite a redução dos custos de transação e dos custos de informação de um acordo financeiro e, dessa forma, é possível captar mais recursos que podem ser utilizados em outros investimentos. Bebencivenga \& Smith (1998) e Luitel \& Khan (1999) destacaram o papel relevante do sistema financeiro como propulsor do crescimento econômico. Por outro lado, uma crescente literatura, como Baldwin (1989), Beck (2003, 2002), Manova (2008, 2013), Greenaway et al. (2007), tem mostrado a importância do desenvolvimento do setor financeiro para o comércio internacional dos países.

De acordo com Beck (2003), além da literatura tradicional de comércio internacional, que considera a dotação de fatores, tecnologia e economias de escala como fontes de vantagem comparativa, o nível de desenvolvimento financeiro também poderia ser um determinante dos fluxos comerciais entre os países. Beck (2002) ressaltou que há uma variedade de canais por meio

\footnotetext{
${ }^{1}$ Foram adotadas medidas como a instituição do Programa de Estímulo à Reestruturação e ao Fortalecimento do Sistema Financeiro (PROER) e do Programa de Incentivo à Redução do Setor Público Estadual na Atividade Bancária (PROES) e a criação do Fundo Garantidor de Crédito (FGC) e outros.
} 
dos quais o nível de desenvolvimento financeiro pode se revelar como uma vantagem comparativa, principalmente em setores que dependem relativamente mais do financiamento externo. O autor afirmou que ao economizar com custos de aquisição e processamento de informações, instituições e mercados financeiros bem desenvolvidos podem ajudar a superar os problemas de risco moral e seleção adversa. Nessas circunstâncias, é possível melhor monitorar as ações dos tomadores de empréstimos e promover o bom funcionamento das transações financeiras, o que favorece a captação de recursos para determinado setor produtivo bem como possibilita a redução dos custos para realização de financiamentos.

Rotineiramente, tanto os produtores que atendem o mercado interno quanto aqueles que realizam o comércio no mercado internacional necessitam de capital externo na produção ${ }^{2}$, já que incorrem com custos iniciais significativos. Esses custos envolvem despesas com desenvolvimento de produtos, pesquisas de marketing, investimentos em equipamentos, compra de insumos intermediários, pagamento a trabalhadores, taxas de aluguel, entre outros, que geralmente precisam ser levados em consideração que a produção e as vendas ocorram. Nesse contexto, para os exportadores as despesas iniciais tornam a sua produção para o mercado internacional ainda mais dependente do financiamento externo, pois apresentam custos adicionais como gastos referentes à personalização do produto e conformidade regulatória de acordo com as exigências do país importador, criação e manutenção de redes de distribuição no mercado externo, custos de comércio como taxas de seguro e frete, entre outros gastos de exportação.

O capital externo pode exercer influência sobre as transações internacionais dos países, pois geralmente é utilizado para cobrir parte dos custos de comércio que não conseguem ser financiados com os lucros acumulados. Portanto, o financiamento torna-se fundamental para cobrir os gastos de produção e exportação e, na maioria das vezes, ocorre sob a forma de empréstimos bancários ou de crédito comercial. Além disso, de acordo com Chor \& Manova (2012), as empresas que participam do comércio internacional podem utilizar o recurso de forma a minimizar as questões burocráticas e demora no envio e entrega de produtos aos parceiros comerciais. Nesse sentido, a presença de mercados financeiros bem desenvolvidos e instituições bancárias eficientes são cruciais para que os produtores tenham maior acesso ao crédito e, assim, possam financiar suas atividades, alcançar o mercado internacional e se tornarem mais competitivos.

Ao se levar em consideração os diferentes setores da economia, é importante salientar que alguns deles, em termos de complexidade e sofisticação tecnológica do processo de produção, duração do ciclo de desenvolvimento e comercialização, possuem maior necessidade de liquidez e são mais dependentes do financiamento externo ${ }^{3}$. Os setores mais produtivos, ao obterem

\footnotetext{
${ }^{2} \mathrm{O}$ capital externo e financiamento externo referem-se aos recursos obtidos junto a investidores e credores, ou seja, são fundos que as firmas obtêm de terceiros sem utilizar suas reservas internas (lucros retidos pela própria empresa para o financiamento).

${ }^{3}$ Por exemplo, alguns setores enfrentam custos iniciais mais elevados, o que de certa forma pode exigir maior necessidade de capital externo. Dado que os ciclos de produção são distintos, a dependência do financiamento para atender as necessidades de liquidez de curto prazo será diferente entre os setores. Além disso, os setores se diferem quanto à defasagem entre o momento em que as despesas de produção são incorridas e as receitas são realizadas, o que também afeta a dependência do capital externo. Consequentemente, alguns setores são mais vulneráveis ao financiamento que outros.
} 
maiores receitas, podem oferecer retornos maiores aos credores e, consequentemente, conseguem captar mais recursos para produção e exportação. Já os setores que não são tão eficientes, apresentam baixa receita líquida e não atraem os investidores, tendo dificuldades em obter financiamento.

Se o país exportador é financeiramente desenvolvido, os setores mais eficientes e que apresentam maior dependência do financiamento externo ${ }^{4}$ tendem a ser mais beneficiados com esses empréstimos e são capazes de elevar suas exportações. Beck (2003, 2002), Manova (2008, 2013), Zavacka (2009), Rajan \& Zingales (1998) verificaram que de fato alguns setores são mais vulneráveis ao financiamento externo, e que em países financeiramente desenvolvidos, os setores que mais se destacaram no mercado internacional foram aqueles que apresentaram maior dependência de capital externo. Os setores que possuem maior necessidade de financiamento de terceiros tendem a ser mais beneficiados quando há expansão de acesso ao crédito e prestação de serviços financeiros de maior qualidade, pois, nessas circunstâncias, conseguem explorar as oportunidades de exportação e se tornam mais competitivos.

Existem diversos estudos que têm feito considerável esforço para analisar os efeitos do desenvolvimento do sistema financeiro sobre o comércio internacional, considerando diferentes abordagens (Beck 2003, 2002, Svaleryd \& Vlachos 2005, Hur et al. 2006, Manova 2008, 2013, Berman \& Héricourt 2010, Berman \& Martin 2012, Zavacka 2009, Chor \& Manova 2012, Chan \& Manova 2015, Héricourt \& Poncet 2013). As pesquisas que abordaram o tema, tanto do ponto de vista teórico quanto empírico, evidenciaram a relevância de estudos nessa área. No entanto, uma análise ainda pouco explorada é o impacto do desenvolvimento do sistema financeiro sobre o comportamento das exportações brasileiras no mercado mundial. O presente estudo, diferentemente dos demais, buscou verificar como o desenvolvimento financeiro e o nível de dependência financeira de determinados setores afetaram as exportações do país.

Paralelamente ao crescimento e estabilização do sistema financeiro nos últimos 20 anos, ocorreu o aumento do comércio internacional do Brasil. Segundo dados do Banco Mundial, no ano de 1995, período em que houve expansão da abertura comercial, o comércio externo como porcentagem do PIB foi de 12,8\%, chegando a 19,8\% em 2014. Especificamente para as exportações, esse valor foi de 11,5\% nesse último ano.

Desse modo, considerando a maior estabilização do sistema financeiro nacional após a implantação do Real, bem como a grande relevância das exportações para a economia brasileira, torna-se importante verificar se de fato o sistema financeiro funciona como um dos determinantes das exportações. $\mathrm{O}$ objetivo geral deste estudo é analisar a relação entre desenvolvimento do sistema financeiro e as exportações brasileiras. Especificamente, pretendeu-se avaliar como o grau de desenvolvimento financeiro afeta o valor exportado pelo Brasil e verificar a relação entre a dependência financeira dos setores selecionados, o grau de desenvolvimento financeiro e as exportações brasileiras em cada setor. Portanto, a contribuição do presente estudo é expandir as informações a respeito dos efeitos do desenvolvimento financeiro sobre o valor das exportações entre 1995 a 2014, período que abrange início da abertura

\footnotetext{
${ }^{4}$ A dependência financeira de cada setor é definida como a necessidade de capital de terceiros para cobrir parte dos custos de produção e exportação. Nesse contexto, no presente estudo considerou-se a dependência financeira, a dependência de financiamento externo e a vulnerabilidade financeira dos setores como sendo sinônimos.
} 
comercial brasileira, crescimento e estabilização do sistema financeiro, até os anos recentes.

Esse conhecimento é importante, pois sendo o desenvolvimento financeiro uma fonte de vantagem comparativa, uma maior concessão de crédito, a existência de instituições financeiras de qualidade e a maior prestação de serviços financeiros, podem levar ao aumento dos investimentos em novas tecnologias, infraestrutura, expansão da capacidade produtiva e, consequentemente, maiores poderão ser as oportunidades brasileiras de exportação, desde que o lucro gerado pelo setor exceda os custos do financiamento. Além disso, o desenvolvimento financeiro, ao proporcionar crescimento das exportações, pode trazer benefícios para a economia como um todo. Tais ganhos estariam associados à geração de emprego e renda, e também à melhoria da produtividade e competitividade das exportações brasileiras.

\section{Referencial Teórico}

\subsection{Desenvolvimento Financeiro e Comércio Internacional}

As teorias clássicas de comércio internacional procuram explicar como as dotações de fatores e as diferenças tecnológicas podem determinar as vantagens comparativas dos países. No entanto, modelos teóricos mais recentes têm buscado mostrar o efeito do desenvolvimento do setor financeiro nos fluxos comerciais por meio da ampliação dos modelos Ricardiano e de HeckscherOhlin. Neste contexto, Kletzer (1987) e Baldwin (1989) desenvolveram uma das primeiras teorias as quais consideram o mercado financeiro como uma fonte de vantagem comparativa.

Kletzer (1987) analisaram a questão do financiamento externo para determinados setores, levando em consideração o papel das instituições e mercados financeiros. Com base no modelo de Heckscher-Ohlin, os autores consideram em seu modelo, dois países, dois setores e dois fatores. Tecnologias, dotação de fatores e preferências do consumidor são assumidas como idênticas nos países. Ambos os setores dependem dos dois fatores (terra e trabalho). Aliado a isso, um setor também depende do financiamento externo para capital de giro. No modelo desenvolvido, o país com menor nível de restrições no mercado de crédito especializa-se no setor que utiliza o financiamento externo. Por outro lado, o país com maiores restrições no mercado de crédito, enfrenta preço mais elevado para realizar o financiamento ou crédito limitado e, portanto, se especializa no setor que não requer financiamento externo.

Baldwin (1989) desenvolveu um modelo de dois países, dois setores e um fator, e considera que a demanda por um dos produtos está sujeita a choques, enquanto o outro setor está livre de tais perturbações. O autor demonstra que as economias com mercados financeiros mais desenvolvidos têm melhores possibilidades de diversificar o risco decorrente do choque de demanda. Portanto, os países financeiramente desenvolvidos são capazes de especializaremse no bem sujeito a algum choque na demanda, já que terão melhores condições de enfrentar tais perturbações.

A partir dos trabalhos realizados por Kletzer (1987) e Baldwin (1989) outros modelos teóricos que tratam da relação entre comércio internacional e sistema financeiro surgiram na literatura, como Beck (2002), Chaney (2005) e Manova (2013). A constatação comum desses autores é que as exportações são particularmente vulneráveis às imperfeições no mercado financeiro, já que 
restrições de crédito podem inibir o investimento e participação no mercado externo. Nessa perspectiva, o modelo teórico proposto por Beck (2002) explica como o grau de desenvolvimento financeiro afeta as decisões de produção, o nível e a estrutura do comércio internacional.

Assim como proposto por Beck (2002), considera-se que existem na economia agentes que vivem por dois períodos. Os agentes nascem com certa quantidade de capital disponível. Os jovens usam esse capital no primeiro período para gerenciar as empresas e a renda resultante é dividida entre consumo e poupança. No início do segundo período, os agentes depositam a poupança que obtiveram com intermediários financeiros e ganham juros $\left(R=1+i^{D}\right)$, que serão consumidos no final da vida. Nessa economia, a cesta de consumo dos indivíduos é composta por dois produtos: o bem homogêneo, alimentos $(x) \mathrm{e}$ os bens manufaturados $\left(y_{j}\right)$ que são produzidos em diferentes variedades. A cesta de consumo pode ser representada por:

$$
C=x^{\delta}\left(\int_{i=0}^{W} y_{j}^{\sigma} d j\right)^{\frac{1-\delta}{\sigma}}
$$

Nesse sentido, para essa função de consumo Cobb-Douglas, o consumidor vai despender da parcela $\delta$ do orçamento com o consumo de alimentos e $1-\delta$ com bens manufaturados. Assumindo que $0<\sigma<1$, os consumidores sempre preferem mais variedades de manufaturas a menos (Beck 2002).

Para os produtores, em cada período, produzem tanto alimentos $(x)$ quanto uma variedade de produtos manufaturados $\left(y_{j}\right)$ :

$$
\begin{gathered}
x=z i=z(k+l) \\
y_{j}=\alpha z i-T=\alpha z(k+l)-T
\end{gathered}
$$

em que $k$ é o capital próprio do produtor, $l$ são empréstimos fornecidos pelos intermediários financeiros e $z$ é um choque de uma firma específica com função de distribuição uniforme $F(z)=z / b$. T são os custos iniciais, que são considerados custos irrecuperáveis, e $\alpha>1$ é um parâmetro de produtividade que faz com que a produção de bens manufaturados seja mais eficiente que a produção de alimentos.

Enquanto a produção de alimentos apresenta rendimentos constantes de escala, o processo produtivo de manufaturas possui retornos crescentes de escala. Antes da produção, empresários e intermediários vão estabelecer um contrato de dívida, de forma a expandir o capital e financiar parte dos custos de produção e exportação. Para verificar o contrato ótimo, é importante reconhecer que os produtores não têm as mesmas informações que os financiadores, ou seja, a informação entre eles não é simétrica. Além disso, os intermediários financeiros enfrentam os custos de financiamento externo.

Em termos de produção interna, o autor evidencia que quando os custos de financiamento externo são menores, o retorno para os produtores de manufaturas é maior que para os produtores de alimentos, uma vez que conseguem explorar economias de escala. Portanto, ao conseguirem obter financiamento 
a um custo mais baixo, o setor manufatureiro que apresenta retornos crescentes a escala, obtém lucros maiores se comparado ao setor de alimentos. Nesse contexto, o desenvolvimento financeiro sob a forma de redução nos custos de financiamento, vai contribuir para o maior crescimento do setor de manufaturados.

Ao considerar uma economia aberta, Beck (2002) analisa um mundo com dois países, doméstico e estrangeiro (resto do mundo), que têm o mesmo tamanho, e apresentam preferências e tecnologias idênticas. A única diferença entre as nações é o nível de desenvolvimento financeiro, determinado pelos custos de financiamento. Considere um equilíbrio sem especialização setorial, de modo que ambas as economias produzam alimentos e bens manufaturados. A eficiência do sistema financeiro de um país vai determinar as vantagens comparativas e a composição dos fluxos comerciais. Isso ocorre pois, se os intermediários financeiros domésticos enfrentam maiores custos de financiamento que o resto do mundo, o país será exportador de alimentos e importador líquido de bens manufaturados. Portanto, com menor nível de desenvolvimento financeiro (custo mais elevado) o país doméstico especializa-se na produção do bem que apresenta retornos constantes de escala, e que, provavelmente, apresenta menor necessidade de capital externo.

Por meio do modelo teórico apresentado, verifica-se que se dois países possuem o mesmo tamanho, preferências e tecnologias, aquele com menores custos de financiamento, ou seja, melhor desenvolvimento financeiro terá maior estoque de capital. Isso permite que esse país explore suas economias de escala, se traduzindo em vantagem comparativa no setor que possui retornos crescentes a escala (manufaturados).

\section{Metodologia}

\subsection{Efeitos do Desenvolvimento Financeiro Sobre as Exportações Brasileiras}

Nesta seção, apresenta-se o modelo empírico empregado no presente estudo, bem como as variáveis incluídas na equação estimada. De forma a atender os objetivos da pesquisa, o modelo é estimado no âmbito das equações gravitacionais, assim como indicado pela literatura (Manova 2013, Berman \& Martin 2012, Bernard et al. 2011, Eaton et al. 2004). Para investigar os efeitos do desenvolvimento do sistema financeiro sobre o valor exportado pelo Brasil e estudar a relação entre a dependência financeira dos setores selecionados, grau de desenvolvimento financeiro e o valor exportado pelo Brasil em cada setor, o modelo estimado pode ser expresso da maneira:

$$
\begin{array}{r}
\ln X_{j i s t}=\beta_{0}+\beta_{1}\left(I D F_{j t}\right)+\beta_{2}\left(I D F_{i t}\right)+\beta_{3} I D F_{j t} * \text { dep.financ. } \\
+\beta_{4} I D F_{i t .} * \text { dep.financ. }_{s}+\beta_{5} \ln \left(P I B_{j t}\right)+\beta_{6} \ln \left(\text { PIB }_{i t}\right) \\
+\beta_{7} \ln \left(\text { dist }_{j i}\right)+\beta_{8} \text { front } . j i_{. j}+\beta_{9} \operatorname{ling} .+\beta_{10} \text { crise } \\
+\beta_{11} \text { crisedepend }_{{ }_{s}}+\beta_{12} \text { Mercosul }+\beta_{13} \ln \left(\text { juros }_{j t}\right) \\
+\beta_{14} \ln \left(\text { BNDES }_{j t}\right)
\end{array}
$$

A variável $X_{j i s t}$ refere-se ao valor nominal das exportações do país $j$ (Brasil) para o país $i$ no setor $s$ no ano $t(t=1995$ a 2014). Em que $i$, representa os 
99 principais parceiros comerciais do Brasil entre 1995 e 2014, que absorveram em média cerca de 99 do total exportado pelo país no período analisado ${ }^{5}$; $s$ corresponde os valores das exportações (US\$) de 28 setores $^{6}$. É importante destacar que esses dados são referentes às exportações brasileiras de 4 e 5 dígitos do SITC Rev.2. No entanto, foi utilizada a tabela de correspondência de nomenclaturas do comércio internacional, desenvolvida pelo WITS, de modo a agregar essas informações nos 28 setores analisados. $\mathrm{O} \ln$ indica as variáveis que foram logaritmizadas.

A estimação de equações gravitacionais, como em (4), pode ser realizada com base em modelos de efeitos fixos. Esses efeitos permitem a inclusão dos termos de resistência multilateral ${ }^{7}$ como fatores não observados na equação, $\mathrm{o}$ que evita o viés causado pela omissão dessas variáveis. A correta definição desses efeitos fixos depende dos objetivos de cada pesquisa. No presente estudo, dado que a estimação do modelo é realizada apenas para o Brasil, as dummies por país de destino $i$ equivalem às dummies para pares de países, o que poderia captar o efeito dos indicadores de desenvolvimento financeiro sobre as exportações brasileiras, não sendo a especificação mais indicada. Ademais, é importante ressaltar que como no estudo utilizou dados de exportações desagregados em 28 setores, portanto, foram incluídos nas equações empíricas os efeitos fixos para cada um dos setores $\left(\alpha_{s}\right)$. Adicionalmente, foram inseridos na análise os efeitos fixos de tempo, $\mu_{t}$.

$I D F_{j t}$ e $I D F_{i t}$ referem-se aos indicadores elaborados para representar o desenvolvimento financeiro do país $j$ e país $i$ no ano $t$, respectivamente. A medida de desenvolvimento financeiro é construída com base em quatro variáveis: crédito privado, passivo líquido, qualidade das instituições financeiras e ativos dos bancos (maiores informações na Seção 3.3).

$\mathrm{IDF}_{j t} . *$ dep. financ. ${ }_{s}$ é a variável de interação entre o nível de desenvolvimento financeiro do país $j$ no ano $t$ e a dependência financeira de cada setor $s$ IDF $_{i t}$ * dep. financ. , refere-se a variável de interação entre o nível de desenvolvimento financeiro do país $i$ no ano $t$ e a dependência financeira de cada setor $s$. A variável dependência de financiamento para cada setor é definida como a parcela das despesas de capital não financiadas com operações de fluxo de caixa interno. Os dados referentes a essa variável foram obtidos diretamente de Laeven \& Klingebiel (2007), que seguem a metodologia de Rajan \& Zingales (1998). Esses autores calcularam a dependência financeira para cada um dos setores com base em dados de empresas norte-americanas de capital aberto, e representa a média para os anos de 1980 a $1999^{8}$. É impor-

\footnotetext{
${ }^{5}$ A lista dos países incluídos na amostra pode ser verificada no Apêndice.

${ }^{6}$ Os setores selecionados para o estudo são referentes ao código ISIC de 3 dígitos: produtos alimentares; bebidas; tabaco; produtos têxteis; vestuário, exceto calçados; produtos de couro; calçados; produtos de madeira, exceto móveis; móveis, exceto de metal; papel e seus produtos; produtos de impressão e publicação; produtos químicos; outros produtos químicos; petróleo refinado; produtos de petróleo e carvão; produtos de borracha; produtos plásticos; cerâmica e porcelana; produtos de vidro; produtos não metálicos; ferro e aço; metais não ferrosos; produtos metálicos; maquinaria, exceto elétrica; maquinaria elétrica; equipamentos de transporte; equipamentos profissionais e científicos; outras indústrias. Esses produtos representaram entre 1995 e 2014 cerca de $62 \%$ do total exportado pelo Brasil e foram escolhidos com base na disponibilidade dos dados referente à dependência financeira de cada setor.

${ }^{7}$ Os termos de resistência multilateral medem a resistência média ao comércio que o país $j$ enfrenta com todos os demais parceiros comerciais. Portanto, são variáveis que captam os custos de comércio referente aos outros parceiros comerciais.

${ }^{8}$ Os dados de dependência financeira para cada setor estão de acordo com Rajan \& Zingales (1998) e Manova $(2008,2013)$, Héricourt \& Poncet (2013). Sendo que essa variável é calculada
} 
tante ressaltar que outros estudos como Manova et al. (2015), que analisaram os impactos de restrições de crédito sobre o comércio internacional e o da atividade multinacional de firmas chinesas no ano de 2005, também utilizaram as informações de Laeven \& Klingebiel (2007). Seguindo essa mesma linha, Dell'Ariccia et al. (2008), Zavacka (2009) e Héricourt \& Poncet (2013) obtiveram os dados de dependência financeira diretamente do estudo de Rajan \& Zingales (1998) ${ }^{9}$.

Segundo Manova (2008) e Rajan \& Zingales (1998), a proxy com base em dados de empresas dos Estados Unidos seria apropriada para a medida de dependência externa pois, esse país possui um dos sistemas financeiros mais avançados e sofisticados, portanto a medida utilizada é razoável para refletir a escolha ideal das firmas ao financiamento. Além disso, é conveniente utilizar os Estados Unidos como país de referência devido ao fato de que os dados para dependência financeira de cada setor são limitados para muitos países, como no caso do Brasil no período analisado.

$P I B_{j t}, P I B_{i t}$ são os respectivos PIB's do país $j$ e país $i$ no ano $t$ (refere-se ao PIB per capita nominal - US\$). Essas variáveis são utilizadas para representar as rendas do país exportador e importador, considerando-se o valor nominal do PIB doméstico e estrangeiro, assim como sugerido pelo modelo teórico gravitacional e diversos estudos que realizaram análises a partir de equações de gravidade (Almeida et al. 2014, Berman \& Martin 2012, Fidrmuc \& Fidrmuc 2016, Chaney 2013, Figueiredo et al. 2016) ${ }^{10}$.

Deve-se destacar que estudos recentes sobre o modelo gravitacional, como Anderson (2010), Baldwin \& Taglioni (2011), Figueiredo et al. (2014), Baltagi et al. (2014) argumentam que o uso do PIB dos países como variável do modelo não é adequado. Os autores consideram que uma alternativa seria retirar essa variável das estimativas e incluir os efeitos fixos de exportador-ano e importador-ano, que captariam os efeitos da renda sobre o comércio e outras características não observáveis específicas de cada país e variantes no tempo. Para o presente estudo, ao excluir o PIB do Brasil $\left(P I B_{j t}\right)$ e o PIB dos países importadores $\left(P I B_{i t}\right)$ e incluir os efeitos fixos de exportador-ano e importadorano, as principais variáveis de interesse, o indicador de desenvolvimento do sistema financeiro do Brasil $\left(I D F_{j t}\right)$ e o desenvolvimento financeiro dos parceiros comerciais $\left(I D F_{i t}\right)$, que variam nas mesmas dimensões dos PIB's (jteit), também deveriam ser retiradas. Nesse sentido, na construção do modelo estimado neste trabalho, optou-se por uma equação gravity-type, seguindo os mesmos procedimentos metodológicos que os adotados nos trabalhos de Manova (2008), Manova (2013) e Chor \& Manova (2012) que, ao analisarem a relação entre o funcionamento do mercado financeiro e os fluxos de comércio, mantiveram a variável "PIB" em suas estimativas.

como as despesas de capital menos o fluxo de caixa e o resultado é dividido pelas despesas de capital para cada setor. Além disso, o valor do indicador refere-se à média entre todas as empresas em cada setor.

${ }^{9}$ No estudo de Rajan \& Zingales (1998), a dependência financeira de cada setor foi calculada para o período de 1980 a 1990.

${ }^{10}$ A justificativa para a inclusão dos PIB's em valores nominais de acordo com Shepherd (2013) parte do fato de que essas variáveis são deflacionadas pelos termos de resistência multilaterais incluídos nos modelos gravitacionais, que são os índices de preços não observados. Assim, se os PIB's fossem deflacionados por algum outro fator, como o deflator implícito do PIB, poderiam não capturar adequadamente os termos de resistência multilateral não observados e gerar resultados viesados. 
Dist $_{j t}$ representa a distância entre o país $j$ (Brasil) e o país $i$, medida pela distância em quilômetros entre as cidades mais populosas de cada país. É comum a utilização dessa proxy para medir a distância entre os países (Almeida et al. 2014, Bittencourt et al. 2016), uma vez que, geralmente, essas cidades apresentam grande participação na atividade econômica e exporta-

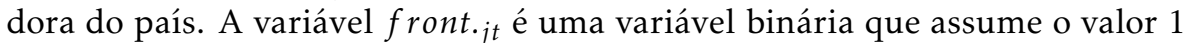
se o país $i$ faz fronteira com o Brasil, e zero, caso contrário. ling. é a dummy que assume o valor 1, se o país $i$ tem a mesma língua oficial que o Brasil, e 0 caso contrário.

A variável crise é a dummy que recebe o valor 1 para os anos de 2008 e 2009, de forma a captar o efeito da crise do subprime. A construção dessa variável baseou-se no estudo de Chor \& Manova (2012), em que a dummy recebeu o valor unitário entre setembro de 2008 a agosto de 2009 . Já a variável crisedepend refere-se ao termo de interação entre a dummy de crise e a dependência financeira de cada um dos setores selecionados.

Mercosul refere-se à dummy que assume o valor 1 se as exportações brasileiras ocorreram para um país membro do Mercosul, ou 0, caso contrário. juros $_{j t}$ representa a taxa de juros real do país $j$ (Brasil) no ano $t$. No presente estudo, a variável utilizada refere-se à taxa de juros de empréstimos ajustada pela inflação, medida pelo deflator do PIB. Autores como Nakabashi et al. (2008), Sonaglio et al. (2010) e Chor \& Manova (2012), destacaram a importância de inserir essa variável nos estudos que levam em conta as relações de comércio entre os países.

$B N D E S_{j t}$ refere-se ao montante desembolsado pelo instrumento público de crédito às exportações do BNDES (BNDES-Exim) no Brasil (país $j$ ) no ano $t^{11}$. Segundo Rossi \& Prates (2013), o BNDES-Exim é o principal mecanismo público nacional de apoio às empresas voltadas ao mercado externo e desde 1990 tem angariado esforços para promover o desenvolvimento de um setor exportador mais dinâmico e integrado internacionalmente. É importante destacar que o sistema público de crédito à exportação tem atuação complementar ao setor privado, buscando suprir lacunas das operações voltadas ao mercado externo cujos prazos ou necessidade de taxas mais competitivas as tornam pouco interessantes para os bancos comerciais.

\subsection{Métodos de Estimação}

Nos estudos que abordaram modelos gravitacionais, o número de observações nulas para o fluxo de comércio tende a ser um problema constante e pode tornar os coeficientes estimados viesados. Outra característica importante no que se refere às equações de gravidade está relacionada à presença de fluxos comerciais discrepantes, dado a heterogeneidade dos padrões de comércio entre os países. Diante desses aspectos em relação aos dados, há na literatura

\footnotetext{
${ }^{11}$ Foram consideradas as duas linhas de financiamento: pré-embarque e pós-embarque. De acordo com Webber \& Dathein (2014) o pré-embarque representa o capital de giro que a empresa exportadora vai utilizar com gastos com matéria-prima e mão de obra para a produção dos bens destinados à exportação. Já o pós-embarque tem como objetivo financiar a comercialização dos bens no mercado internacional. Deve-se ressaltar que o outro instrumento público de apoio às exportações, o PROEX, que é gerido pelo Banco do Brasil com recursos disponibilizados no Orçamento da União, não é incluído no presente estudo. Isto pois, como uma das variáveis utilizadas para a construção do indicador de desenvolvimento financeiro refere-se ao crédito concedido por bancos e instituições financeiras ao setor privado, a inclusão da variável indicativa do montante de financiamento à exportação do PROEX poderia gerar dupla contagem.
} 
constante discussão sobre qual seria a forma mais adequada de estimar o modelo gravitacional. Na presença de fluxo zero, para um modelo log-linear, as estimativas utilizando o Método de Mínimos Quadrados Ordinários (MQO) levam em consideração apenas os valores positivos de comércio, eliminando, assim, as observações nulas. Conforme Silva \& Tenreyro (2006), os modelos estimados por MQO na presença de fluxos comerciais iguais a zero e de heterocedasticidade fornecem estimativas viesadas.

A literatura (Helpman et al. 2007, Martin \& Pham 2008, Figueiredo et al. 2014, Berman \& Martin 2012) tem buscado métodos alternativos para tratar as questões de fluxos de comércio nulo e heterocedasticidade presentes nos modelos de gravidade. Silva \& Tenreyro (2006) destacaram que para contornar esses problemas, as equações de gravidade devem ser estimadas na forma multiplicativa (não linear) por meio do método de Pseudo Poisson-MaximumLikelihood(PPML) $)^{12}$. O uso desse método justifica-se pelo fato de apresentar estimativas consistentes na presença de heterocedasticidade e fornecer estimativas robustas quando há fluxos zero na amostra.

A partir do trabalho de Silva \& Tenreyro (2006), outros métodos surgiram na literatura como forma alternativa de tratar os fluxos nulos na análise. Dentre eles, tem-se o método de seleção amostral de dois estágios de Heckman (1979). Essa abordagem permite avaliar o efeito de variáveis explicativas sobre o comércio bem como verificar a probabilidade de ocorrência do mesmo. Este método, além de corrigir o problema dos fluxos de comércio nulo, evita o viés de seleção de Heckman e o viés de assimetria entre os fluxos comerciais (Almeida et al. 2014) ${ }^{1314}$.

Outro método de estimação adotado no estudo referiu-se à Regressão Quantílica com correção para a seletividade amostral. Esse método é semelhante ao modelo de Seleção Amostral de Heckman. O procedimento consiste em estimar, no primeiro estágio, um modelo probabilístico (probit) para a decisão de ocorrência do comércio. Após a estimação do modelo probit calcula-se a razão inversa de Mills, que é incorporada na equação de interesse (segundo estágio). Na estimação do segundo estágio, seguindo Machado \& Santos Silva (2013), é empregada a técnica de regressão quantílica que apresenta erros-padrão assintoticamente válidos na presença de heterocedasticidade.

Essa abordagem econométrica, além de tratar o número de valores nulos para a variável dependente e a heterocedasticidade, possibilita uma análise mais profunda acerca das relações entre as variáveis de interesse. Permite verificar a heterogeneidade do impacto de variáveis explicativas sobre as exportações brasileiras, por meio da análise ao longo de diferentes quantis. Assim, esse método é viável para analisar como o poder de explicação das variáveis independentes sobre a variável dependente pode ser distinto ao se levar em consideração os diferentes pontos da distribuição da amostra analisada. De acordo com Figueiredo et al. (2016), outra justificava para utilizar o método de regressão quantílica é que a função quantil é invariante às transformações

\footnotetext{
${ }^{12}$ Para mais informações a respeito do modelo de PPML ver Silva \& Tenreyro (2006).

${ }^{13}$ Outros trabalhos como Helpman et al. (2007), Martin \& Pham (2008), Almeida et al. (2014) utilizaram o modelo de seleção amostral em equações gravitacionais.

${ }^{14}$ Assim como apontado pela literatura, (Linders \& De Groot 2006, Helpman et al. 2007, Martin \& Pham 2008, Almeida et al. 2014), em relação ao modelo de Seleção Amostral no contexto de equações gravitacionais, as estimativas foram realizadas por meio do método de Máxima Verossimilhança (ML) já que, como argumentado por esses autores, a estimação ML gera resultados mais robustos e consistentes se comparado ao método de Heckman em dois estágios.
} 
monotônicas. Como consequência, é capaz de identificar os parâmetros tanto de modelos log-lineares quanto de modelos exponenciais, o que não seria possível nas estimativas do PPML (modelo exponencial), já que a condição de identificação desse método, de que a média condicional é igual a 1, impossibilita a identificação de modelos log-lineares. O modelo gravitacional é estimado empregando-se os métodos PPML, Seleção Amostral de Heckman e Seleção Quantílica.

Os problemas da simultaneidade entre a proxy de desenvolvimento do sistema financeiro e o valor exportado, bem como a causalidade reversa entre o PIB e as exportações brasileiras, têm sido comumente citados na literatura de comércio internacional (Manova 2008, Héricourt \& Poncet 2013, Do \& Levchenko 2007). Quanto à possível endogeneidade da variável representativa da renda dos países (PIB), Almeida et al. (2014) e Souza \& Burnquist (2011) destacaram a presença desse problema. No entanto, não encontraram instrumentos apropriados para corrigi-lo. Seguindo as recomendações teóricas do modelo gravitacional, estudos recentes, como Figueiredo et al. (2016) e Baltagi et al. (2014), têm retirado o PIB das estimações e incorporado efeitos fixos país importador-ano e país exportador-ano, que são proxies para os termos de resistência multilateral. Todavia, essa abordagem não pode ser utilizada na presente pesquisa, já que a inclusão desses efeitos fixos poderia captar os impactos do desenvolvimento financeiro sobre as exportações do Brasil, o que comprometeria o objetivo principal do estudo.

Em relação à possível endogeneidade das variáveis referentes aos indicadores de desenvolvimento financeiro, Héricourt \& Poncet (2013) argumentaram que ao utilizarem dados ao nível de firma, a questão da causalidade reversa entre o comércio e as proxies relacionadas ao ambiente financeiro é atenuada. A utilização de variáveis instrumentais seria o procedimento adequado para corrigir a endogeneidade. Entretanto, dado que é difícil encontrar instrumentos que representem corretamente os indicadores de desenvolvimento financeiro, deve-se considerar que os resultados encontrados nesta pesquisa podem conter esse possível viés da endogeneidade.

\subsection{Elaboração dos Indicadores de Desenvolvimento Financeiro}

No que se refere à proxy usada para o desenvolvimento financeiro, o padrão da literatura é tratar o crédito privado em relação ao PIB como principal medida, já que reflete a disponibilidade de recursos em um país. Todavia, diversos estudos (King \& Levine 1993, Beck et al. 2000, Beck 2003, 2002, Svaleryd \& Vlachos 2005, Manova 2013, Atiq \& Haque 2015) apresentaram outras variáveis proxy como o passivo líquido, os indicadores do mercado de ações, ativos dos bancos, entre outros, que são importantes para representar o desenvolvimento financeiro. Considerar apenas o crédito concedido ao setor privado pode não ser uma medida ideal de desenvolvimento financeiro, já que outras características como a qualidade institucional, medidas referentes à intensidade, à eficiência e ao acesso nos mercados financeiros também devem ser levadas em conta para representar o desenvolvimento financeiro de um país. Por meio da análise fatorial, propõe-se a construção de um índice para sintetizar os indicadores de desenvolvimento financeiro.

A Tabela 1 apresenta as variáveis que foram utilizadas na elaboração do índice. A escolha dessas variáveis deveu-se à disponibilidade de dados para os países da amostra no período de 1995 a 2014. A inclusão do crédito pri- 
vado reflete a disponibilidade de financiamento e evidencia o crédito emitido exclusivamente para o setor privado, não considerando o crédito concedido ao governo, agências governamentais e empresas públicas. Portanto, com base nessa variável o desenvolvimento do sistema financeiro refere-se à capacidade de fornecimento de financiamento ao setor privado. Assim, níveis mais elevados de crédito privado indicam maior prestação de serviços financeiros e maior volume de crédito e, consequentemente, maior o nível de desenvolvimento financeiro.

A justificativa de se utilizar o indicador passivo líquido relaciona-se ao fato de os intermediários financeiros captarem recursos de curto prazo, convertendoos em empréstimos de longo prazo, permitindo às firmas um horizonte de investimento mais longo, favorecendo o alcance do mercado estrangeiro. Portanto, o tamanho do setor financeiro pode estar positivamente relacionado com a prestação e a qualidade dos serviços, sugerindo assim, bom desenvolvimento do sistema financeiro.

A variável ativos dos bancos é uma medida de intensidade financeira e, de acordo com Atiq \& Haque (2015), pode representar a oferta de moeda, excluindo a moeda em circulação. Assim, quanto maiores os ativos dos bancos, mais eficiente tende a ser o mercado de crédito, o que pode indicar maior nível de desenvolvimento do sistema financeiro. A variável referente à qualidade das instituições financeiras é incluída na análise, pois o bom funcionamento dessas instituições pode ser considerado um fator importante para que os países apresentem um sistema financeiro bem desenvolvido. Nessas circunstâncias, os intermediários financeiros enfrentam menor risco e incerteza, o que favorece a melhoria na qualidade e quantidade de serviços financeiros prestados.

Tabela 1: Descrição das variáveis utilizadas para construção do indicador do desenvolvimento financeiro

\begin{tabular}{c|l}
\hline \multicolumn{1}{c|}{ Variável } & \multicolumn{1}{c}{ Descrição } \\
\hline Crédito privado & $\begin{array}{l}\text { Total de crédito concedido por bancos e ou- } \\
\text { tras instituições financeiras ao setor privado } \\
\text { como proporção do PIB }\end{array}$ \\
\hline Passivo líquido & $\begin{array}{l}\text { Exigíveis de curto prazo do sistema finan- } \\
\text { ceiro como fração do PIB, refere-se ao tama- } \\
\text { nho do sistema de intermediação financeira } \\
\text { (intensidade financeira) }\end{array}$ \\
\hline Ativos dos bancos & $\begin{array}{l}\text { Total de ativos mantidos por bancos comerci- } \\
\text { ais e outras instituições financeiras que acei- } \\
\text { tam depósitos transferíveis, como proporção } \\
\text { do PIB }\end{array}$ \\
\hline $\begin{array}{l}\text { Qualidade } \\
\text { instituições } \\
\text { econômico- } \\
\text { financeiras }\end{array}$ & $\begin{array}{l}\text { Variável composta pelos indicadores: liber- } \\
\text { dade de negócios, liberdade comercial, liber- } \\
\text { dade fiscal, liberdade monetária, liberdade fi- } \\
\text { nanceira e liberdade de investimentos }\end{array}$ \\
\hline
\end{tabular}

Fonte: Elaborado pelos autores.

Para a construção do índice de desenvolvimento financeiro é utilizada a 
análise fatorial $(\mathrm{AF})^{15}$ considerando as variáveis descritas na Tabela 2 para os 100 países da amostra (Brasil + 99 parceiros) ao longo dos anos de 1995 a 2014. Portanto, é empregada uma AF em dados em painel e gerado um escore fatorial para cada país em cada ano. Posteriormente, o índice resultante da análise fatorial é considerado como uma medida de desenvolvimento financeiro do Brasil e os países da amostra. Desse modo, após realizada a análise fatorial esse indicador é incorporado na Equação (4).

\subsection{Fonte de Dados}

Os dados utilizados neste trabalho são de periodicidade anual e compreenderam o período de 1995 a 2014, que abrange o início da estabilização do sistema financeiro brasileiro e crescimento das exportações com o início da abertura comercial, até os anos recentes. Os valores das exportações brasileiras (US\$) foram obtidos junto ao United Nations Commodity Trade Statistics Database (UNCOMTRADE).

As variáveis representativas do desenvolvimento financeiro de cada país (crédito privado, passivo líquido e total de ativos dos bancos), os dados referentes ao PIB per capita nominal (US\$ bilhões), e taxa de juros real do país $j$ (taxa de juros de empréstimo ajustada pelo deflator do PIB), foram obtidas junto ao Banco Mundial (2016) (Global Financial Development e World Development Indicators). Já os indicadores da qualidade das instituições econômicofinanceiras foram extraídos do Heritage Foundation (2016). Os dados de dependência externa para cada setor estão de acordo com Rajan \& Zingales (1998), Manova $(2008,2013)$, Héricourt \& Poncet (2013) e foram obtidos diretamente de Laeven \& Klingebiel (2007). As variáveis de distância geográfica, fronteira e a língua comum entre o país $j$ e país $i$, foram obtidas do Centre D'Estudes Prospective et d'Informations Internationales (CEPII 2015). Os desembolsos do BNDES (BNDES-Exim) para o financiamento às exportações foram obtidos do site do BNDES.

\section{Resultados e Discussão}

\subsection{Efeitos do Desenvolvimento do Sistema Financeiro Sobre o Valor das Exportações Brasileiras}

Esta seção contém as estimativas do modelo gravitacional descrito na Seção 3.1 deste trabalho. Os resultados apresentados basearam-se na estimação dos coeficientes da Equação (4) por meio do método de regressão quantílica com correção de seletividade amostral. Deve-se destacar que a equação também é estimada com base nos métodos de seleção amostral de Heckman por máxima verossimilhança e PPML. Porém, como os resultados obtidos nos diferentes métodos foram semelhantes, optou-se por apresentá-los nas Tabelas 4 e 5 do Apêndice.

É importante ressaltar que os resultados da Tabela 2 referem-se aos coeficientes obtidos para a equação de interesse (segundo estágio) por meio da téc-

\footnotetext{
${ }^{15}$ A motivação para a utilização dessa técnica é que reduz os problemas causados pela correlação esperada entre algumas das variáveis de desenvolvimento financeiro, o que poderia causar a muticolinearidade, caso cada uma dessas medidas fossem incluídas separadamente nos modelos empíricos. Ademais, deve-se destacar que o índice varia de 0 a 1, e os valores mais próximos de 1 indicam um maior nível de desenvolvimento financeiro.
} 
nica de regressão quantílica sendo utilizados os quantis 0,$25 ; 0,50$ e 0,75, para representar volume exportado (US\$) baixo, médio e alto, respectivamente.

Para as estimativas obtidas da equação de seleção (primeiro estágio), conside-

rou-se a língua comum como variável utilizada para atender as condições de identificação, assim como Almeida et al. (2014) e Vollrath \& Hallahan (2009). Helpman et al. (2007) consideraram que essa variável deve ser capaz de indicar custos fixos ao comércio. Nesse sentido, a dummy referente ao compartilhamento de idioma pode ser adequada para representar esse tipo de barreira comercial ${ }^{16}$. Ademais, é importante destacar que a regressão quantílica é estimada usando-se o estimador proposto por Machado \& Santos Silva (2013), em que os erros-padrão e a estatística $t$ são assintoticamente válidos na presença de heterocedasticidade. Conforme exposto na Tabela 2, a razão inversa de Mills e a razão inversa de Mills ao quadrado ${ }^{17}$ são estatisticamente significativas, o que indica que o problema de seleção amostral não pode ser ignorado.

Em todos os quantis analisados, a variável indicativa da renda do país exportador, $\ln \left(P I B_{j t}\right)$, apresentou coeficiente positivo, porém é estatisticamente significativo apenas no quantil 0,75 . Esse resultado sugeriu que o crescimento da renda do Brasil, ao permitir que as firmas domésticas se tornem mais produtivas, tende a favorecer o aumento do valor das exportações no quantil mais elevado. Em conformidade com esse aspecto, Fidrmuc \& Fidrmuc (2008), que analisaram o impacto do conhecimento de línguas estrangeiras sobre o comércio internacional, verificaram relação positiva entre a renda do exportador e o valor das exportações nos diferentes pontos de distribuição da amostra. Para os quantis 0,25 e 0,50, assim como o resultado obtido pelo estimador de Heckman por ML, os coeficientes estimados para a variável PIB do Brasil não foram estatisticamente significativos, o que é plausível ao se levar em conta o valor exportado de setores específicos, como no presente estudo.

A variável referente ao PIB do país importador, $\ln \left(P I B_{i t}\right)$, também apresentou coeficiente positivo e estatisticamente significativo nos três quantis considerados na análise empírica. Assim, acredita-se que variações positivas no nível de renda dos parceiros comerciais brasileiros tendem a aumentar a demanda por bens importados, o que contribui para elevar as exportações do Brasil. Esses resultados corroboram aqueles obtidos por Bilici (2016), que em seu estudo sobre os determinantes do comércio internacional de serviços no Reino Unido, encontrou resultado semelhante para a variável PIB do importador, ou seja, incrementos na renda do país parceiro afetaram positivamente o valor das exportações em todos os quantis.

Em se tratando do coeficiente estimado para a variável distância, $\ln \left(\right.$ dist. $\left._{\text {.ji }}\right)$, assim como sugerido pela teoria, verificou-se impacto negativo e estatisticamente significativo sobre o valor das exportações em todos os quantis. Portanto, verifica-se que a distância eleva os custos e reduz o comércio entre o Brasil e os parceiros, e esse efeito é observado nos três quantis. Constatou-se

\footnotetext{
${ }^{16}$ Helpman et al. (2007) consideraram, também, a variável "religião comum" no primeiro estágio, mas os resultados foram semelhantes aos obtidos quando utilizaram o "idioma comum" como variável excluída do modelo de seleção amostral.

${ }^{17}$ De modo a verificar a presença do viés de seleção amostral, calculou-se a razão inversa de Mills com base nas estimativas obtidas no primeiro estágio e, posteriormente, essa variável é incluída no segundo estágio (equação de interesse). Segundo Buchinsky $(1998,2001)$, a razão inversa de Mills baseia-se na expansão em séries de potência. Assim como proposto por Buchinsky (2001) e Coelho et al. (2015), no presente estudo é utilizada a série de potência de ordem dois.
} 
Tabela 2: Efeitos do desenvolvimento do sistema financeiro sobre o valor das exportações brasileiras: estimativas para a regressão quantílica

\begin{tabular}{|c|c|c|c|}
\hline & \multicolumn{3}{|c|}{ Coeficientes } \\
\hline Variáveis/Quantis & q0,25 & $\mathrm{q} 0,5$ & $q 0,75$ \\
\hline $\ln \left(P I B_{j t}\right)$ & $\begin{array}{c}0,220^{N S} \\
(0,3247) \\
\end{array}$ & $\begin{array}{c}0,234^{N S} \\
(0,2697) \\
\end{array}$ & $\begin{array}{c}0,373^{*} \\
(0,2241) \\
\end{array}$ \\
\hline $\ln \left(P I B_{i t}\right)$ & $\begin{array}{c}0,456^{* * *} \\
(0,0180)\end{array}$ & $\begin{array}{c}0,526^{* * *} \\
(0,0153)\end{array}$ & $\begin{array}{c}0,575^{* * *} \\
(0,0144)\end{array}$ \\
\hline $\ln \left(\right.$ dist. $\left._{\cdot i t}\right)$ & $\begin{array}{c}-0,365^{* * *} \\
(0,0550)\end{array}$ & $\begin{array}{c}-0,713^{* * *} \\
(0,0398) \\
\end{array}$ & $\begin{array}{c}-0,820^{* * *} \\
(0,0321) \\
\end{array}$ \\
\hline$(I D F \cdot j t)$ & $\begin{array}{c}-1,805^{N S} \\
(8,1474)\end{array}$ & $\begin{array}{c}1,664^{N S} \\
(6,6901)\end{array}$ & $\begin{array}{c}-2,957^{N S} \\
(5,7025)\end{array}$ \\
\hline$I D F \cdot{ }_{j t} d e p \cdot s$ & $\begin{array}{r}2,781^{* *} \\
(1,1926) \\
\end{array}$ & $\begin{array}{c}3,094^{* * *} \\
(0,9879) \\
\end{array}$ & $\begin{array}{c}2,267^{* *} \\
(0,9282)\end{array}$ \\
\hline$\left(I D F ._{i t}\right)$ & $\begin{array}{c}1,384^{* * *} \\
(0,1948)\end{array}$ & $\begin{array}{c}1,896^{* * *} \\
(0,1479)\end{array}$ & $\begin{array}{c}1,388^{* * *} \\
(0,1497)\end{array}$ \\
\hline$I D F \cdot{ }_{i t} d e p \cdot{ }_{s}$ & $\begin{array}{r}-0,750^{* *} \\
(0,3823)\end{array}$ & $\begin{array}{r}-0,568^{* *} \\
(0,2522)\end{array}$ & $\begin{array}{c}-1,132^{* * *} \\
(0,2285)\end{array}$ \\
\hline front.ji & $\begin{array}{c}1,325^{* * *} \\
(0,1201)\end{array}$ & $\begin{array}{c}1,802^{* * *} \\
(0,0887)\end{array}$ & $\begin{array}{c}1,229^{* * *} \\
(0,0537)\end{array}$ \\
\hline ling. & - & - & - \\
\hline Mercosul & $\begin{array}{c}2,114^{* * *} \\
(0,1133)\end{array}$ & $\begin{array}{c}0,557^{* * *} \\
(0,0751)\end{array}$ & $\begin{array}{c}0,329^{* * *} \\
(0,0509)\end{array}$ \\
\hline Crise & $\begin{array}{c}-0,021^{N S} \\
(0,1329)\end{array}$ & $\begin{array}{c}-0,097^{N S} \\
(0,1129)\end{array}$ & $\begin{array}{c}-0,064^{N S} \\
(0,0874)\end{array}$ \\
\hline crisedep.s & $\begin{array}{c}-0,080^{N S} \\
(0,1502)\end{array}$ & $\begin{array}{c}0,017^{N S} \\
(0,1477)\end{array}$ & $\begin{array}{c}0,018^{N S} \\
(0,1069) \\
\end{array}$ \\
\hline $\ln \left(j u r o s_{j t}\right)$ & $\begin{array}{c}0,175^{N S} \\
(0,4820) \\
\end{array}$ & $\begin{array}{c}0,533^{N S} \\
(0,4030) \\
\end{array}$ & $\begin{array}{c}0,068^{N S} \\
(0,3364) \\
\end{array}$ \\
\hline $\ln \left(B N D E S_{j t}\right)$ & $\begin{array}{c}0,258^{N S} \\
(0,2822) \\
\end{array}$ & $\begin{array}{c}0,325^{N S} \\
(0,2483) \\
\end{array}$ & $\begin{array}{c}0,1564^{N S} \\
(0,1887)\end{array}$ \\
\hline Mills & $\begin{array}{c}-28,231^{* * *} \\
(2,9934) \\
\end{array}$ & $\begin{array}{c}-15,493^{* * *} \\
(2,7280) \\
\end{array}$ & $\begin{array}{c}-12,089^{* * *} \\
(2,8911) \\
\end{array}$ \\
\hline Mills $^{2}$ & $\begin{array}{c}27,8507^{* * *} \\
(3,3917) \\
\end{array}$ & $\begin{array}{c}14,723^{* * *} \\
(3,0736)\end{array}$ & $\begin{array}{c}10,911^{* * *} \\
(3,289)\end{array}$ \\
\hline Constante & $\begin{array}{c}16,245^{* * *} \\
(3,6263)\end{array}$ & $\begin{array}{c}15,047^{* * *} \\
(3,0683)\end{array}$ & $\begin{array}{c}19,707^{* * *} \\
(2,4966)\end{array}$ \\
\hline No Obs.: & & 46509 & \\
\hline
\end{tabular}

Fonte: Resultados da Pesquisa.

Nota 1: Erros-padrão robusto em parênteses ${ }^{* * *}$ significativo a $1 \%$; ${ }^{* *}$ significativo a 5\%; NS - Não significativo. Nota 2: Os subscritos $j i$ referem-se às relações entre o país $j$ e o país $i$. O subscrito $j$ refere-se ao Brasil, o subscrito $i$ aos principais parceiros comerciais, o subscrito $s$ representa os setores e $t$ indica o ano de análise. Nota 3: Foi realizado o teste de Wald e rejeitou-se a hipótese de igualdade dos parâmetros entre os quantis, o que mostrou a adequação da regressão quantílica. 
que para maiores valores de exportação, quantil 0,75, a distância teve maior influência. É importante destacar que esses resultados estão de acordo com outros trabalhos encontrados na literatura, tais como os estudos de Figueiredo et al. (2014) e Fidrmuc \& Fidrmuc (2016), que também verificaram coeficiente negativo para a variável distância.

Quanto ao efeito do desenvolvimento do sistema financeiro brasileiro sobre as exportações do país, o coeficiente estimado da variável, $\left(I D F_{j t}\right)$, não apresentou significância estatística em nenhum dos quantis analisados, o que pode ser explicado por alguns fatores. O índice de desenvolvimento financeiro do Brasil, calculado por meio da análise fatorial, embora tenha aumentando ao longo dos anos, ainda apresenta um valor relativamente baixo. Do total de 100 países analisados, o índice do Brasil foi o $48^{\circ}$, obtendo uma média de 0,2608 entre 1995 e 2014. O sistema financeiro brasileiro apesar de ter evoluído em termos de concessão de crédito ao setor privado, ter expandido os ativos dos bancos e a disponibilidade dos serviços financeiros, ainda apresenta dificuldades. Os principais problemas podem estar relacionados com a qualidade das instituições econômico-financeiras, dificuldade de acesso ao crédito, elevadas taxas de juros, entre outras características que podem afetar de maneira negativa o desempenho do sistema financeiro nacional. Portanto, esses fatores podem explicar a não influência do desenvolvimento financeiro do Brasil sobre o valor exportado no quantis 0,25, 0,50 e 0,75. Ademais, as evidências reportadas na presente pesquisa estão em conformidade com os estudos de Manova (2013), Héricourt \& Poncet (2013), Berman \& Héricourt (2010) que também verificaram o impacto estatisticamente não significante do desenvolvimento financeiro sobre o valor exportado por determinados países.

Já os coeficientes estimados para a variável de interação entre o nível de desenvolvimento financeiro do Brasil e a dependência financeira de cada setor, em todos os quantis, apresentaram-se estatisticamente significativos e positivamente relacionados com as exportações brasileiras. Ao se levar em consideração o fato de que os setores se diferem quanto à necessidade de capital de terceiros, quanto maior o desenvolvimento financeiro maior o valor exportado nesses setores, independentemente do volume exportado ter sido classificado em baixo, médio ou alto (quantis $0,25,0,50$ e 0,75 ). Portanto, diante da grande importância dos recursos externos para os setores com menor montante de recursos internos (mais dependentes de financiamento), o bom funcionamento do sistema financeiro ao proporcionar maior acesso ao crédito, redução dos riscos e incertezas e fornecimento de serviços financeiros de qualidade, se faz ainda mais relevante para promover as exportações desses setores. Resultados similares são comumente encontrados na literatura acerca do tema, podendo citar os estudos de Hur et al. (2006), Svaleryd \& Vlachos (2005) e Zavacka (2009).

$\mathrm{O}$ indicador de desenvolvimento financeiro dos países parceiros mostrouse estatisticamente significativo ao nível de $1 \%$ e com sinal positivo nos três quantis. Portanto, o melhor ambiente financeiro nos países importadores pode auxiliar a reduzir os custos de importação, bem como os riscos que envolvem a atividade, o que, por sua vez, tende a impactar positivamente as exportações brasileiras. Com base na Tabela 2, constatou-se que esse efeito se mantém independentemente do quantil considerado, no entanto, o impacto é maior para o quantil mediano.

Em relação à variável $I D F_{i t} d e p_{s}$, o coeficiente estimado indicou que o am- 
biente financeiro dos principais parceiros comerciais exerceu influência negativa sobre o valor exportado pelo Brasil nos setores mais dependentes de recursos de terceiros. Uma possível explicação para esse efeito negativo é que o desenvolvimento financeiro do país importador pode permitir que os bens produzidos internamente se tornem mais competitivos e passem a concorrer com os produtos brasileiros, o que pode afetar de maneira negativa o valor das exportações do Brasil nos setores que mais dependem de financiamento.

Para a variável front. $j i$, que representa a existência de fronteira comum entre o Brasil e os países importadores, os coeficientes estimados em todos os quantis foram positivos e estatisticamente significativos ao nível de $1 \%$. Esse resultado é pertinente, uma vez que se espera que o compartilhamento de fronteiras contribua para reduzir os custos de transporte no comércio, afetando de maneira positiva o valor das exportações brasileiras. Além disso, a magnitude dos coeficientes indicou que os menores quantis, sobretudo o quantil 0,50, foram os mais beneficiados. Nesse contexto, Fidrmuc \& Fidrmuc (2016), também verificaram coeficientes positivos e significativos para a variável fronteira em todos os quantis, sendo que nos quantis intermediários foram encontrados os maiores coeficientes.

O fato de o país parceiro fazer parte do Mercosul (Mercosul) apresentou efeito positivo sobre o valor das exportações brasileiras em todos os quantis. De acordo com Oliveira \& Badin (2013), a participação em acordos regionais, como o Mercosul, tende a reduzir os custos de comércio, já que há diminuição e eliminação de tarifas, aumento do poder de barganha, entre outros benefícios. Consequentemente, a redução desses custos tende a elevar o valor exportado pelo Brasil para os países membros do bloco. Observou-se que para menores volumes exportados (quantil 0,25), o fato de o país importador pertencer ao Mercosul exerceu maior influência. Esse resultado indicou a relevância da participação em acordos regionais de comércio de modo a expandir o acesso aos mercados internacionais, sobretudo para os menores valores de exportação.

Quanto aos efeitos da crise do subprime sobre as exportações brasileiras, verificou-se que o coeficiente da dummy crise não apresentou significância estatística nos três quantis analisados, revelando que as exportações do Brasil para os seus 99 principais parceiros comerciais não foram afetadas nesse período. Uma possível justificativa para esse resultado é que, nos anos anteriores à crise houve crescimento das exportações brasileiras alavancadas pela expansão da demanda internacional, ascensão da China e aumento do preço de commodities, o que permitiu ao país acumular reservas e assim, apresentar melhores condições de enfrentar a crise econômica mundial. Além disso, nesse período a estrutura econômico-financeira do Brasil havia se tornado mais sólida, o que, de certo modo, amenizou os efeitos negativos da crise. Desse modo, tais medidas podem ter contribuído para a não influência da crise do subprime sobre o valor exportado pelo país.

Em relação à variável de interação entre a dummy crise e a dependência financeira dos setores, verificou-se que a crise do subprime não exerceu influência sobre as exportações dos setores que se diferem quanto à dependência de capital de terceiros, já que o coeficiente estimado não é estatisticamente significativo em nenhum dos quantis analisados $(0,25 ; 0,50$ e 0,75$)$. Se considerarmos que os setores que mais dependem de financiamento tendem a enfrentar maiores dificuldades para obterem recursos em períodos de crise, os resultados encontrados na presente pesquisa podem não ser condizentes com 
o esperado. Contudo, as evidências empíricas para a variável crisedepend.s se assemelham às encontradas por Zavacka (2009) e Chor \& Manova (2012) ${ }^{18}$.

Para a taxa de juros do Brasil, $\ln \left(\right.$ juros $\left._{j t}\right)$, constatou-se que essa variável não afetou o valor das exportações, e esse efeito é observado tanto para os menores valores exportados quanto para os maiores valores. Esse resultado não é surpreendente, uma vez que existem na literatura estudos que também encontraram, em especificações alternativas de seu modelo, coeficientes não significativos para essa variável, tais como Nakabashi et al. (2008) e Chor \& Manova (2012).

No que se refere à variável $\ln \left(B N D E S_{j t}\right)$, o coeficiente estimado não apresentou significância estatística em nenhum dos três quantis. Alguns fatores podem justificar a não significância estatística dessa variável. Segundo informações do relatório da CNI (2016), esse instrumento público de financiamento é considerado pelas empresas exportadoras como sendo pouco relevante. Além disso, muitas vezes, os exportadores têm dificuldades em obter informações sobre o programa, o que contribui para reduzir a utilização desse mecanismo de financiamento à exportação.

\section{Conclusão}

Diante da intensificação da globalização, incluindo a globalização financeira e a abertura comercial do Brasil no final da década de 1980, o debate de como o desenvolvimento financeiro pode afetar o comércio internacional se faz importante. Nesse sentido, dada a maior estabilização do sistema financeiro nacional após o Plano Real, bem como a grande relevância das exportações para a economia brasileira, o presente estudo analisou como o grau de desenvolvimento financeiro tem afetado as exportações brasileiras em determinados setores, no período de 1995 a 2014.

Com base nos resultados obtidos para três diferentes métodos de estimação, foi possível verificar coeficientes estatisticamente significativos e sinais conforme o esperado para a maioria das variáveis gravitacionais e de controle. De maneira geral, os resultados indicaram que o desenvolvimento financeiro brasileiro não é importante estatisticamente para determinar as suas exportações. Contudo, quando se analisou o grau de dependência financeira dos setores, encontrou-se relação positiva e significativa entre o desenvolvimento financeiro nacional e o valor exportado, confirmando a hipótese de que o bom funcionamento do sistema financeiro exerce maior influência nas exportações dos setores mais dependentes de capital externo. Além disso, na estimação da regressão quantílica, resultados semelhantes a esses foram obtidos para os três quantis analisados, ou seja, tanto para menores montantes exportados pelo Brasil quanto para os maiores valores de exportação.

A relação positiva entre o desenvolvimento financeiro brasileiro e o valor das exportações nos setores mais dependentes de financiamento evidenciou a importância de o país angariar esforços para aperfeiçoar o sistema financeiro nacional. Estes avanços devem estar relacionados à maior disponibilidade de crédito na economia, aumento no ativo dos bancos, à expansão do tamanho do setor de intermediação financeira, à melhoria na qualidade das

\footnotetext{
${ }^{18}$ É importante destacar que Zavacka (2009) consideraram em sua análise crises bancárias entre 1980 e 2000, e não especificamente a crise do subprime.
} 
instituições econômico-financeiras e facilidade de acesso ao crédito. $\mathrm{O}$ ambiente financeiro mais desenvolvido pode levar ao aumento dos investimentos em tecnologia, infraestrutura, expansão da capacidade produtiva, bem como auxiliar na redução dos custos de comércio, riscos e incertezas das transações financeiras. Como consequência, maior pode ser o valor exportado pelo Brasil, principalmente nos setores mais dependentes de financiamento.

Como sugestão para futuros trabalhos, indica-se que sejam incorporados dados ao nível de firma e para um maior número de setores. Um estudo considerando as firmas brasileiras pode mostrar evidências mais claras sobre a relação entre o nível de desenvolvimento financeiro e as exportações. Além disso, ao utilizarem dados ao nível de firma, a questão da causalidade reversa entre o comércio e a proxy relacionada ao ambiente financeiro pode ser atenuada.

\section{Agradecimento}

Os autores agradecem o apoio financeiro recebido da FAPEMIG, por meio do edital Demanda Universal 2015, para a realização da pesquisa.

\section{Referências Bibliográficas}

Almeida, F. M., Gomes, M. F. M. \& Silva, O. M. (2014), 'Notificações aos acordos TBT e SPS: diferentes objetivos e resultados sobre o comércio internacional de agroalimentos', Revista de Economia e Sociologia Rural 52(1), 157-176.

Anderson, J. E. (2010), 'The gravity model', National Bureau of Economic Research (w16576).

Atiq, Z. \& Haque, E. (2015), Financial development and economic growth: the role of financial liberalization, in 'Centre for Growth and Business Cycle Research Discussion Paper Series', Univeristy of Manchester.

BACEN (2015), Relatório de Evolução Sistema Financeiro Nacional. Banco Central do Brasil. Disponível em: <www.bcb.gov.br>. Acesso em agosto de 2015.

BACEN (2017), Relatório de evolução sistema financeiro nacional, Banco Central do Brasil, BACEN.

URL: Disponivel em: <www.bcb.gov.br>

Baldwin, R. (1989), Exporting the capital markets: comparative advantage and capital market imperfections, Amsterdam, North-Holland.

Baldwin, R. \& Taglioni, D. (2011), 'Gravity chains: Estimating bilateral trade flows when parts and components trade is important', National Bureau of Economic Research (w16672), 1-22.

Baltagi, B. H., Egger, P. \& Pfaffermayr, M. (2014), Panel data gravity models of international trade, Working Paper.

Banco Mundial (2016), Global financial development. URL: Disponivel em <http://www.worldbank.org/en/publication/gfdr/data /global-financial-development-database $>$ 
Bebencivenga, V. R. \& Smith, B. D. (1998), 'Economic development and financial depth in a model with costly financial intermediation', Research in Economics 52(4), 363-386.

Beck, T. (2002), 'Financial development and international trade. Is there a link?', Journal of International Economics 57, 107-131.

Beck, T. (2003), 'Financial dependence and international trade', Review of International Economics 11(2), 296-316.

Beck, T., Demirg, Á-Kunt, A. \& Levine, R. (2000), 'A new data base on financial development and structure', World Bank Economic Review pp. p. 597-605.

Berman, N. \& Héricourt, J. (2010), 'Financial factors and the margins of trade: evidence from cross-country firm-level data', Journal of Development Economics 93(2), 206-217.

Berman, N. \& Martin, P. (2012), 'The vulnerability of Sub-Saharan Africa to financial crises: the case of trade', IMF Economic Review 60(3), 329-364.

Bernard, A. B., Redding, S. J. \& Schott, P. K. (2011), 'Multiproduct firms and trade liberalization', The Quarterly Journal of Economics 126(3), 1271-1318.

Bilici, O. (2016), International trade in a competitive world: empirical evidence from the UK, 207p. Tese de Doutorado em Filosofia, PhD thesis, University of Essex, UK.

Bittencourt, G. M., Mattos, L. B. \& Lima, J. M. (2016), 'Heterogeneidade institucional e o ingresso de investimento direto estrangeiro na economia brasileira', Estudos Econômicos 46(2), 281-310.

Buchinsky, M. (1998), 'The dynamics of changes in the female wage distribution in the USA: a quantile regression approach', Journal of Applied Econometrics 13, 1-30.

Buchinsky, M. (2001), 'Quantile regression with sample selection: estimating women's return to education in the U.S', Empirical Economics 26, 87-113.

CEPII (2015), Databases, Centre D'Estudes Prospective et d'Informations Internationales.

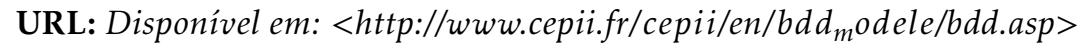

Chan, J. M. L. \& Manova, K. (2015), 'Financial development and the choice of trade partners', Journal of Development Economics 116, 122-145.

Chaney, T. (2005), 'Liquidity Constrained Exporters', University of Chicago Mimeo .

Chaney, T. (2013), The gravity equation in international trade: an explanation, National Bureau of Economic Research, in 'Working Paper', number 19285.

Chor, D. \& Manova, K. (2012), 'Off the cliff and back: credit conditions and international trade during the global financial crisis', Journal of International Economics 87, 117-33. 
CNI (2016), Desafios à competitividade das exportações brasileiras, Technical report, Confederação Nacional da Indústria.

URL: Disponivel em $:<h t t p: / / w w w . p o r t a l d a i n d u s t r i a . c o m . b r \$ / c n i \$ / p u b l i c a c o e s$ -e-estatisticas/publicacoes $\$ / 2016 \$ / 8 \$ / 8,1166 \$ /$ desafios-competitividade-dasexportacoes-brasileiras.html>

Coelho, D., Kubota, L. C. \& Figueiredo, C. O. (2015), 'O impacto da adoção de ERP na produtividade das firmas industriais no Brasil', Produtividade no Brasil p. 171.

Dell'Ariccia, G., Detragiache, E. \& Rajan, R. (2008), 'The real effect of banking crises', Journal of Financial Intermediation 17, 89-112.

Do, Q. \& Levchenko, A. A. (2007), 'Comparative advantage, demand for external finance, and financial development', Journal of Financial Economics 86(3), 796-834.

Eaton, J., Kortum, S. \& Kramarz, F. (2004), 'Dissecting trade: firms, industries, and export destinations', American Economic Review 94(2), 150-154.

Fidrmuc, J. \& Fidrmuc, J. (2008), 'Foreign Languages and Trade: What are you sinking about?'.

Fidrmuc, J. \& Fidrmuc, J. (2016), 'Foreign languages and trade: evidence from a natural experimente', Empirical Economics 50(2), 31-49.

Figueiredo, E., Lima, L. R., Loures, A. \& Oliveira, C. (2014), 'Uma análise para o efeito-fronteira no Brasil', Revista Brasileira de Economia 68(4), 481496.

Figueiredo, E., Lima, L. R. \& Schaur, G. (2016), 'The effect of the Euro on the bilateral trade distribution', Empirical Economics 50(1), 17-29.

Global Competitiveness Report (2015), The global competitiveness report 2014-2015, Technical report.

URL: Disponivel em: < http://www.weforum.org/reports/global-competitivenessreport-2014-2015>

Greenaway, D., Guariglia, A. \& Kneller, R. (2007), 'Financial factors and exporting decisions', Journal of International Economics 73(2), 377-395.

Heckman, J. J. (1979), 'Sample selection bias as a specification error', Econometrica 47(1), 153-161.

Helpman, E., Melitz, M. \& Rubinstin, Y. (2007), Trading partners and trading volumes, in 'NBER Working Paper Series', number 12927, Working Paper.

Heritage Foundation (2016), Index of economic freedom, Disponível em:< http://www.heritage.org/index/about>.

Hur, J., Raj, M. \& Riyanto, Y. (2006), 'Financeand trade: a cross-country empirical analysis on the impact of financial development and asset tangibility on international trade', World Development 34(10), 1728-1741.

Héricourt, J. \& Poncet, S. (2013), 'Exchange rate volatility, financial constraints, and trade: empirical evidence from Chinese firms', The World Bank Economic Review 29(3), 550-578. 
King, R. \& Levine, R. (1993), 'Finance and growth: Schumpeter might be right', Quarterly Journal of Economics 108, p. 717-737.

Kletzer, K. P. (1987), 'Bardhan, credit markets and patterns of international trade', Journal of Development Economics 27, 57-70.

Laeven, L. \& Klingebiel, D. (2007), 'Banking crises, financial dependence, and growth', Journal of Financial Economics 84(1), 187-228.

Linders, G. \& De Groot, H. L. F. (2006), 'Estimation of the gravity equation in the presence of zero flows', Tinbergen Institute Discussion Paper (06-072/3).

Luitel, K. \& Khan, M. (1999), 'A quantitative reassessment of the financegrowth nexus: evidence from a multivariate VAR', Journal of Development Economics 60, 381-405.

Machado, J. A. F. \& Santos Silva, J. M. C. (2013), Quantile regression and heteroskedasticity, department of economics edn, University of Essex.

Manova, K. (2008), 'Credit constraints, equity market liberalizations and international trade', Journal of International Economics 76, 33-47.

Manova, K. (2013), 'Credit constraints, heterogeneous firms, and international trade', Review of Economic Studies 80, 711-744.

Manova, K., Wei, S. \& Zhang, Z. (2015), 'Firm exports and multinational activity under credit constraints', Review of Economics and Statistics 97(3), 574588.

Martin, W. \& Pham, C. S. (2008), 'Estimating the gravity equation when zero trade flows are frequent', MPRA Paper.

Nakabashi, L., Cruz, M. J. V. \& Scatolin, F. D. (2008), 'Efeitos do câmbio e juros sobre as exportações da indústria brasileira', Revista de Economia Contemporânea $12(3)$.

Oliveira, I. T. M. \& Badin, M. R. S. (2013), Tendências regulatórias nos acordos preferenciais de comércio no século XXI: os casos de Estados Unidos, União Europeia, China e Índia, Brasília, IPEA.

Rajan, R. \& Zingales, L. (1998), 'Financial dependence and growth', American Economic Review 88, 559-586.

Rossi, P. \& Prates, D. (2013), 'Financiamento às exportações no Brasil', Revista Análise Econômica 31(59), 203-230.

Shepherd, B. (2013), The gravity model of international trade: a user guide, Artnet Gravity Modeling Initiative.

Silva, E. N. \& Porto Júnior, S. S. (2006), 'Sistema financeiro e crescimento econômico: uma aplicação de regressão quantílica', Economia aplicada 10(3), 425-442.

Silva, J. M. C. S. \& Tenreyro, S. (2006), 'The log of gravity', The Review of Economics and Statistics 88(4). 
Sonaglio, C. M., Zamberlan, C. O., Lima, J. E. \& Campos, A. C. (2010), 'Evidências de desindustrialização no Brasil: uma análise com dados em painel', Economia Aplicada 14(4), 347-372.

Souza, J. P. \& Burnquist, H. L. (2011), 'Facilitação de comércio e impactos sobre o comércio bilateral', Revista de Estudos Econômicos 41(1), 91-118.

Svaleryd, H. \& Vlachos, J. (2005), 'Financial markets, the pattern of industrial specialization and comparative advantage: evidence from OECD countries', European Economic Review 49, 113-144.

Vollrath, T. L. \& Hallahan, C. B. (2009), Economic costs and payoffs of bilateral/regional trade agreements, Annual Meeting, Agricultural and Applied Economics Association, Milwaukee.

Webber, S. L. \& Dathein, R. (2014), A atuação do BNDES-Exim como fortalecedor das exportações brasileiras no período 2000-2012, in 'Texto para discussão', number 4, Universidade Federal do Rio Grande do Sul, Faculdade de Ciências Econômicas.

Zavacka, V. (2009), 'Banking crises and exports: lessons from the past', World Bank Policy Research Working Paper (5016).

\section{Apêndice}

Principais parceiros comerciais do Brasil incluídos na amostra: Argélia, Alemanha, Panamá Angola, Gana, Paraguai, Argentina, Grécia, Peru Austrália, Guatemala, Filipinas, Áustria, Haiti, Polônia Bahamas, Honduras, Portugal, Bangladesh, Hong Kong, Romênia, Bélgica, Hungria, Rússia, Benim, Islândia, Arábia Saudita, Bolívia, Índia, Senegal, Bulgária, Indonésia, Singapura, Cabo Verde, Irã, Eslovênia, Camarões, Irlanda, África do Sul, Canadá, Israel, Espanha, Chile, Itália, Sri Lanka, China, Jamaica, Santa Lúcia, Colômbia, Japão, Suriname, Congo, Jordânia, Suécia, Costa Rica, Quênia, Suíça, Costa do Marfim, Coreia do Sul, Tanzânia, Croácia, Kuwait, Tailândia, Chipre, Líbano, Togo, República Checa, Lituânia, Trinidade e Tobago, Dinamarca, Malásia, Tunísia, República Dominicana, Malta, Turquia, Equador, México, Ucrânia, Egito, Moçambique, Emirados Árabes Unidos, El Salvador, Marrocos, Reino Unido, Finlândia, Países Baixos, Estados Unidos, França, Nicarágua, Uruguai, Gabão, Nigéria, Venezuela, Gâmbia, Omã, Vietnã, Geórgia, Paquistão, Iémen. 
Tabela 3: Médias, desvios-padrão, valores mínimos e máximos das variáveis da amostra, 1995 a 2014

\begin{tabular}{|c|c|c|c|c|}
\hline Variáveis & Média & Desvio-padrão & Mínimo & Máximo \\
\hline 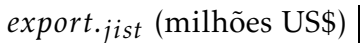 & 28,597 & 169,826 & 0 & $9.421,936$ \\
\hline dist. $j i_{(\mathrm{km})}$ & $9.203,201$ & $4.019,673$ & $1.134,650$ & $18.549,610$ \\
\hline PIB ${ }_{j t}($ per capita - US\$) & $6.757,566$ & $3.439,733$ & $2.805,717$ & $13.039,120$ \\
\hline$P I B_{i t}($ per capita - US\$) & $12.700,230$ & $15.575,590$ & 158,469 & $88.002,610$ \\
\hline$D F_{j t}$ & 0,261 & 0,042 & 0,189 & 0,336 \\
\hline$I D F_{i t}$ & 0,296 & 0,153 & 0,000 & 1,000 \\
\hline dep.financ.s & $-0,1621$ & 0,3618 & $-1,140$ & 0,720 \\
\hline front.ji & 0,081 & 0,273 & 0 & 1 \\
\hline ling. & 0,040 & 0,197 & 0 & 1 \\
\hline Mercosul & 0,040 & 0,197 & 0 & 1 \\
\hline Crise & 0,100 & 0,300 & 0 & 1 \\
\hline$B N D E S_{j t}$ (milhões US\$) & 4494,536 & 2701,587 & 377,6 & 11255,18 \\
\hline juros $_{j t}$ & 44,837 & 15,934 & 18,630 & 77,617 \\
\hline $\mathrm{N}^{\circ}$ de Observações: & & 55440 & & \\
\hline
\end{tabular}

Fonte: Resultados da pesquisa.

Nota: Os subscritos $j i$ referem-se às relações entre o país $j$ e o país $i$. O subscrito $j$

refere-se ao Brasil, o subscrito $i$ aos principais parceiros comerciais, o subscrito $s$

representa os setores e $t$ refere-se ao ano de análise. 
Tabela 4: Resultados das estimativas da equação gravitacional (4) por meio do modelo de seleção amostral de Heckman, período de 1995 a 2014

\begin{tabular}{|c|c|c|c|}
\hline \multirow{2}{*}{ Variáveis } & \multicolumn{3}{|c|}{ Seleção Amostral - Heckman } \\
\hline & Coeficiente & Erro-padrão & p-valor \\
\hline $\ln \left(P I B_{j t}\right)$ & 0,890 & 0,755 & $0,238^{N S}$ \\
\hline $\ln \left(P I B_{i t}\right)$ & 0,494 & 0,012 & $0,000^{* * *}$ \\
\hline $\ln \left(\right.$ dist.ji $\left._{. j}\right)$ & $-0,493$ & 0,034 & $0,000^{* * *}$ \\
\hline$I D F_{j t}$ & $-1,195$ & 5,820 & $0,837^{N S}$ \\
\hline$I D F_{j t} d_{e p \cdot s}$ & 3,203 & 0,883 & $0,000^{* * *}$ \\
\hline$I D F_{i t}$ & 1,224 & 0,130 & $0,000^{* * *}$ \\
\hline$I D F_{i t} d_{e p \cdot s}$ & $-0,490$ & 0,239 & $0,040^{* *}$ \\
\hline fron $_{j i}$ & 1,200 & 0,071 & $0,000^{* * *}$ \\
\hline ling & - & - & - \\
\hline Mercosul & 1,260 & 0,089 & $0,000^{* * *}$ \\
\hline Crise & 0,231 & 0,256 & $0,367^{N S}$ \\
\hline crisedepend.s & 0,002 & 0,119 & $0,984^{N S}$ \\
\hline $\ln \left(\right.$ juros $\left._{j t}\right)$ & 0,174 & 0,394 & $0,658^{N S}$ \\
\hline $\ln \left(B N D E S_{j t}\right)$ & 0,206 & 0,210 & $0,326^{N S}$ \\
\hline $\mathrm{N}^{\circ}$ Obs. & 55440 & & \\
\hline $\mathrm{N}^{\circ}$ Obs. Cens. & 8931 & & \\
\hline Wald $X^{2}$ & 16800 & $0,000^{* * *}$ & \\
\hline Teste de Wald & 447,76 & $0,000^{* * *}$ & \\
\hline
\end{tabular}

Fonte: Resultados da pesquisa.

Nota 1: Os erros-padrão robustos foram estimados pelo método de White. ${ }^{* * *}$ significativo a $1 \%$; ${ }^{* *}$ significativo a $5 \%$; ${ }^{*}$ significativo a $10 \%$; NS - Não significativo. A Tabela 4 mostra os coeficientes obtidos para a equação de interesse. Nas estimativas da equação de seleção, diferentemente da equação de interesse, incluiu-se a variável língua comum, que é a chamada variável de seleção, de modo a atender às condições de identificação. 
Tabela 5: Resultados das estimativas da equação gravitacional (4) por meio do PPML, período 1995 a 2014

\begin{tabular}{|c|c|c|c|}
\hline Variáveis & Coeficiente & Erro-padrão Robusto & p-valor \\
\hline $\ln \left(P I B_{j t}\right)$ & $-0,003$ & 0,029 & $0,902^{N S}$ \\
\hline $\ln \left(P I B_{i t}\right)$ & 0,068 & 0,001 & $0,000^{* * *}$ \\
\hline $\ln \left(\right.$ dist $_{j i}$ & $-0,078$ & 0,004 & $0,000^{* * *}$ \\
\hline$I D F_{j t}$ & 0,967 & 0,743 & $0,193^{N S}$ \\
\hline$I D F_{j t}$ dep $_{s}$ & 0,110 & 0,140 & $0,430^{N S}$ \\
\hline$I D F_{i t}$ & 0,314 & 0,016 & $0,000^{* * *}$ \\
\hline$I D F_{i t} d_{e p} \cdot s$ & $-0,267$ & 0,034 & $0,000^{* * *}$ \\
\hline front. $j i$ & 0,297 & 0,007 & $0,000^{* * *}$ \\
\hline ling. & 0,161 & 0,007 & $0,000^{* * *}$ \\
\hline Mercosul & 0,056 & 0,007 & $0,000^{* * *}$ \\
\hline Crise & 0,014 & 0,011 & $0,239^{N S}$ \\
\hline crisedep.s & $-0,004$ & 0,016 & $0,798^{N S}$ \\
\hline $\ln \left(\right.$ juros $\left._{j t}\right)$ & 0,078 & 0,044 & $0,079^{*}$ \\
\hline $\ln \left(B N D E S_{j t}\right)$ & 0,045 & 0,025 & $0,079^{*}$ \\
\hline
\end{tabular}

Fonte: Resultados da pesquisa. Nota: ${ }^{* * *}$ significativo a $1 \% ;{ }^{* *}$ significativo a $5 \%$; ${ }^{*}$ significativo a $10 \%$; NS - não significativo. 
